\title{
Cyclohexanyl Peptide Nucleic Acids (chPNA) for preferential RNA binding: Effective tuning of Dihedral angle $\beta$ in Peptide Nucleic Acid for DNA/RNA discrimination
}

T.Govindaraju, Vaijayanti A. Kumar* and Krishna N. Ganesh*a

${ }^{a}$ Division of Organic Chemistry (Synthesis), National Chemical Laboratory, Pune 411008, India.

Email: kn.ganesh@ncl.res.in, va.kumar@ncl.res.in 
Table of contents

\begin{tabular}{|c|c|c|}
\hline S1 & General experimental procedures & 2 \\
\hline S2-S3 & Synthesis of $a e g / c h / c p$ PNA oligomers and schematic representation. & 2 \\
\hline $\mathbf{S 4}$ & CD-signatures of $c h$ PNA and $c p$ PNA monomer ethyl esters. & 5 \\
\hline S5-S6 & HPLC profiles of aegPNA 9, $c h$ PNA 10, $c h$ PNA 11, $c p$ PNA 12, and $c p$ PNA 13. & 6 \\
\hline $\mathbf{S 7}$ & MALDI-TOF spectra of aegPNA 9, $c h$ PNA 10, and $c p$ PNA 12. & 8 \\
\hline $\mathbf{S 8}$ & HPLC and MALDI-TOF data of PNAs 9-13 and 18-22, & 9 \\
\hline S9 & Experimental procedures for $\mathrm{UV}-T_{\mathrm{m}}$ and $\mathrm{CD}$ measurements. & 10 \\
\hline S10 & $\begin{array}{l}\text { CD-curves of single stranded } a e g \text { PNA 9, } c h \text { PNA 10, } c h \text { PNA 11, } c p \text { PNA 12, and } \\
c p \text { PNA } 13 \text { and their duplexes with DNA } 14 \text { and RNA } 15 \text { respectively. }\end{array}$ & 11 \\
\hline S11 & CD melting curves for PNAs 9-11 with DNA 14 & 12 \\
\hline S12 & UV-melting curves of aegPNA 9, chPNA 10, chPNA 11 with RNA 15 and RNA 17 & 13 \\
\hline S13 & $\begin{array}{l}\text { UV-melting curves of } c p \text { PNA 12, and } c p \text { PNA } 13 \text { with DNA } 14 \text { and } 16 \text { (antiparallel } \\
\text { and parallel) and }\end{array}$ & 14 \\
\hline $\mathbf{S 1 4}$ & $\begin{array}{l}\text { UV-melting curves of } c p \text { PNA 12, and } c p \text { PNA } 13 \text { with RNA } 15 \text { and } 17 \text { (antiparallel } \\
\text { and parallel). }\end{array}$ & 15 \\
\hline $\mathbf{S 1 5}$ & HPLC profiles of aegPNA 18, chPNA 19, chPNA 20, chPNA 21, and $c h$ PNA 22. & 16 \\
\hline S16 & $\begin{array}{l}\text { MALDI-TOF spectra of } a e g \text { PNA 18, } c h \text { PNA 19, } c h \text { PNA 20, } c h \text { PNA 21, and } c h \text { PNA } \\
\text { 22. }\end{array}$ & 17 \\
\hline S17 & $\begin{array}{l}\text { UV-melting curves of aegPNA 18, chPNA 19, chPNA 20, chPNA 21, and chPNA } 22 \\
\text { with DNA (antiparallel) and RNA (antiparallel and parallel). }\end{array}$ & 18 \\
\hline S18 & MALDI-TOF of $c p$ PNA 27 & 20 \\
\hline S19 & RP HPLC of $c p$ PNA 27 & 21 \\
\hline $\mathbf{S 2 0}$ & 18-mer $c p$ PNA 27 and DNA RNA sequences (mismatch studies) & 22 \\
\hline $\mathbf{S 2 1}$ & UV.melting profiles of cpPNA 27:DNA/RNA duplexes & 23 \\
\hline
\end{tabular}


General Experimental Procedure: Melting points of samples were determined in open capillary tubes and are uncorrected. FTIR spectra were recorded using $\mathrm{KBr}$ pellets. Column chromatographic separations were performed using silica gel 60-120 mesh, solvent systems gradient 10-25\% EtOAc/Pet ether and pure DCM to $3 \% \mathrm{MeOH} / \mathrm{DCM} .{ }^{1} \mathrm{H}$ and ${ }^{13} \mathrm{C}$ spectra were obtained on $200 \mathrm{MHz}$ and $500 \mathrm{MHz}$ NMR spectrometers. Mass spectra were obtained either by FAB or LCMS techniques. PNA Oligomers were characterized by RP HPLC, C18 column and MALDI-TOF mass spectrometry. The enzyme Amano-PS was obtained as a gift from Amano Pharmaceuticals, Japan.

\section{S2-3}

Solid phase peptide synthesis of PNA oligomers 
The unmodified mixed aegPNA decamer 1 (Table 1) for use as a control sequence was synthesized incorporating monomers on MBHA (methyl benzhydryl amine) resin functionalized by L-lysine as a linker improve the solubility of the PNA oligomers. The initial loading value of the resin was $2.5 \mathrm{meq} / \mathrm{g}$ and the coupling reagents HBTU, HOBt and DIEA in DMF/DMSO were used. The $c h$ PNA and $c p$ PNA thymine monomers were incorporated into aegPNA oligomer $\mathbf{1}$ at three thymine positions by standard solid phase synthesis (Figure 3).

Cleavage of the PNA Oligomers from The Solid Support: The oligomers are cleaved from the solid support, using strong acid trifluoromethane sulphonic acid (TFMSA) in the presence of trifluoro acetic acid (TFA) ("Low, High TFMSA-TFA method") which yields oligomer with amide at their $C$-terminus. A cleavage time of $2-2.5 \mathrm{~h}$ at room temperature was found to be optimum. The side chain protecting groups are also cleaved during this cleavage process. After cleavage reaction, the oligomer was precipitated from methanol with dry diethylether. 


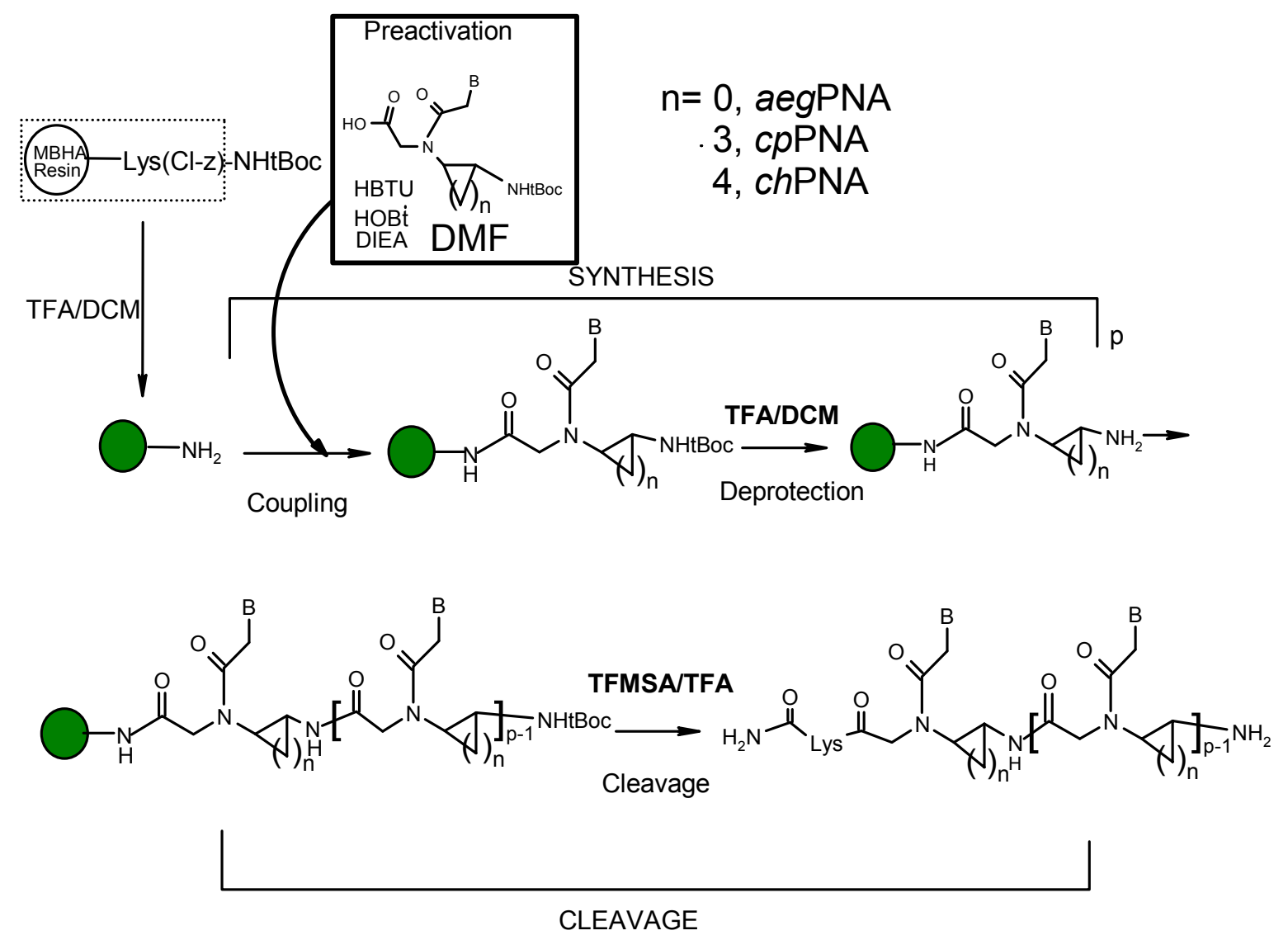

Figure 3. Schematic representation of solid phase synthesis of PNA oligomers

Purification of the PNA Oligomers: All the cleaved oligomers were subjected to initial gel filtration. The purity of the so obtained oligomers were checked by analytical RP HPLC (C18 column, $\mathrm{CH}_{3} \mathrm{CN}: \mathrm{H}_{2} \mathrm{O}$ system), which shows more than $65-70 \%$ purity. These were subsequently purified by reverse phase HPLC on a semi preparative C18 column. The purity of the oligomers was again ascertained by analytical RP-HPLC and their integrity was confirmed by MALDI-TOF mass spectrometric analysis (Table 1).

The complementary DNA oligonucleotides were synthesized on Applied Biosystems ABI 3900 High Throughput DNA Synthesizer using standard $\beta$-cyanoethyl phosphoramidite chemistry. The oligomers were synthesized on polystyrene solid support, followed by ammonia treatment. The oligonucleotides were desalted by gel filtration, their purity was ascertained by RP HPLC on a C18 column to be more 
than $98 \%$ and were used without further purification in the biophysical studies of PNAs. The complementary RNA oligonucleotides were obtained commercially. 

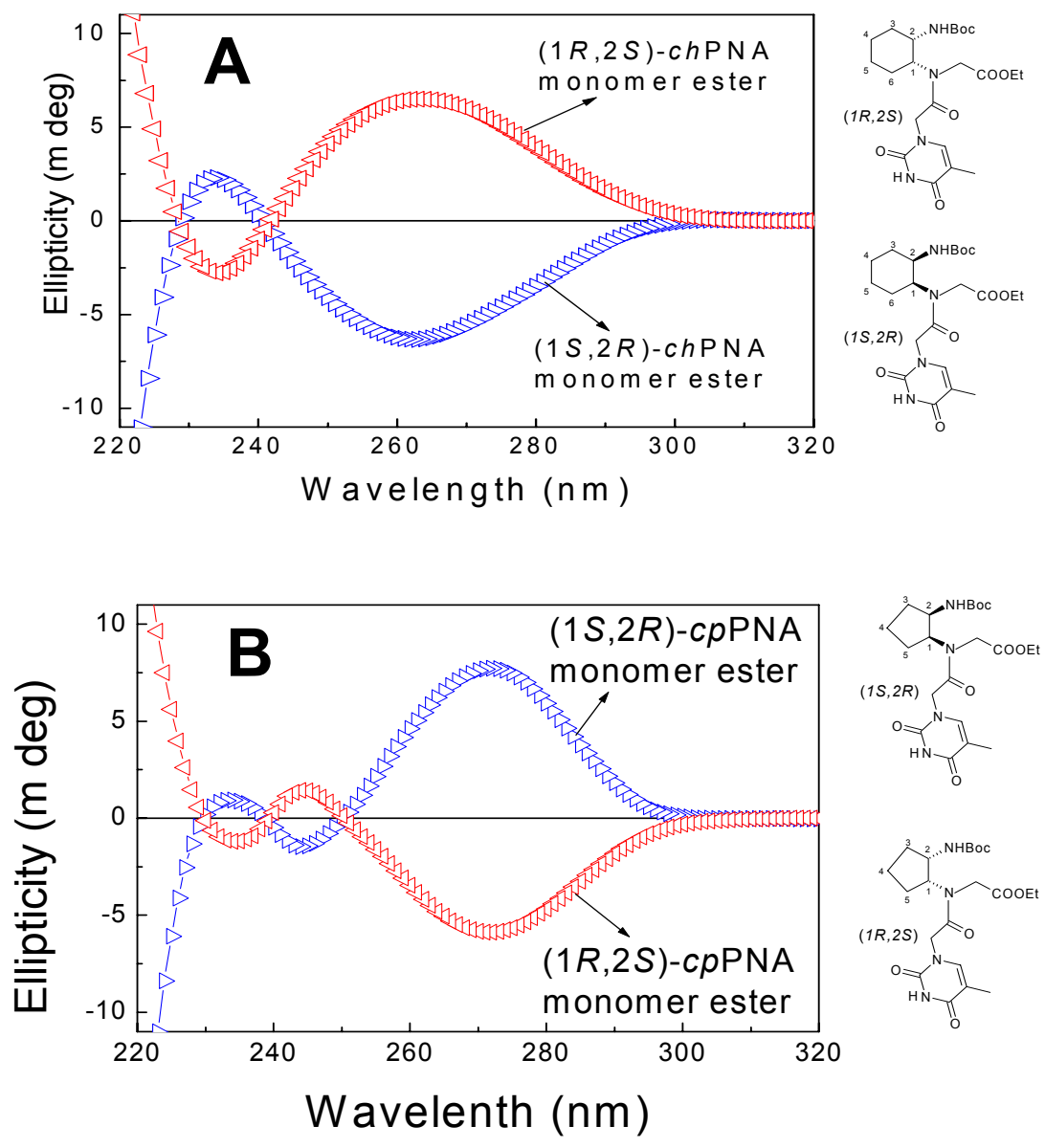

Figure 2. CD-signatures of A: $c h \mathrm{PNA}$-thymine monomer esters B: $c p$ PNA-thymine monomer esters. Measured in methanol (concentration, $1 \mu \mathrm{g} / \mathrm{ml}$ ). 
S5 HPLC profile of aegPNA 9

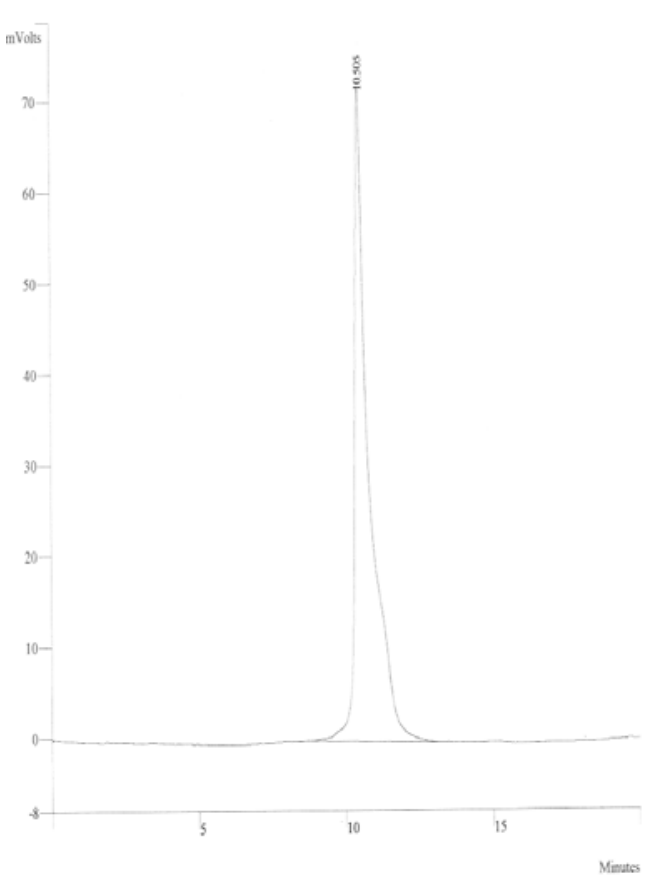

HPLC profile of $c h$ PNA 10

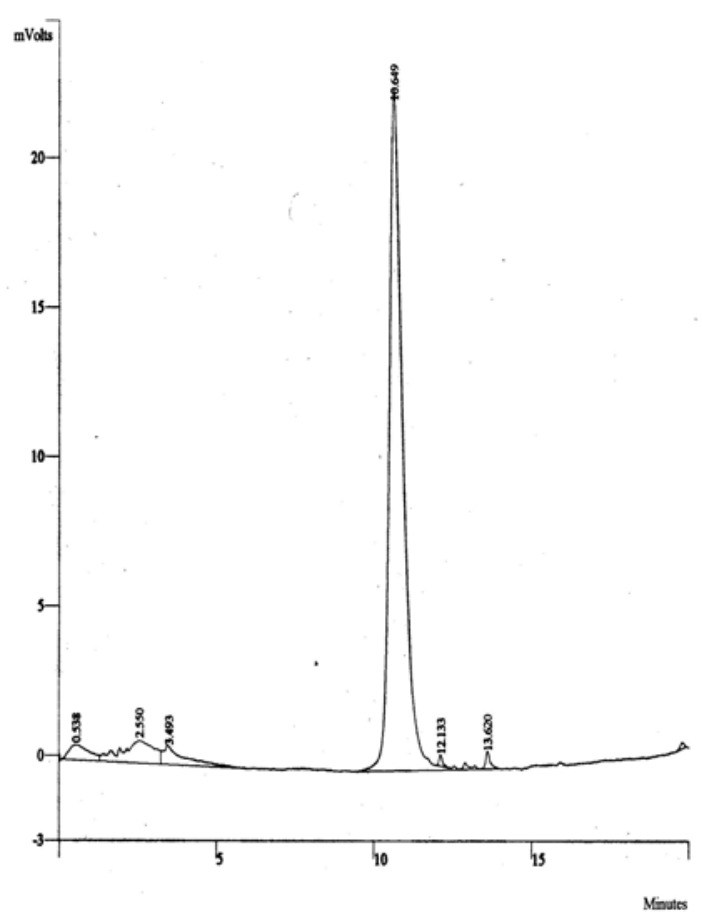

HPLC profile of $c h$ PNA 11

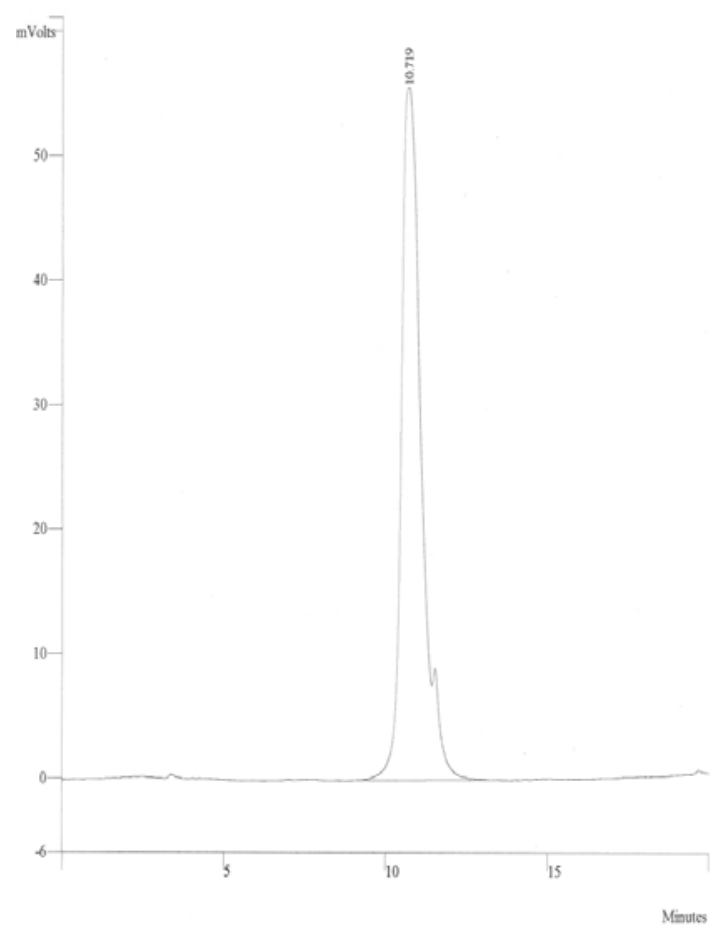


S6

HPLC profile of $c p$ PNA 12

HPLC profile of $c p$ PNA 13
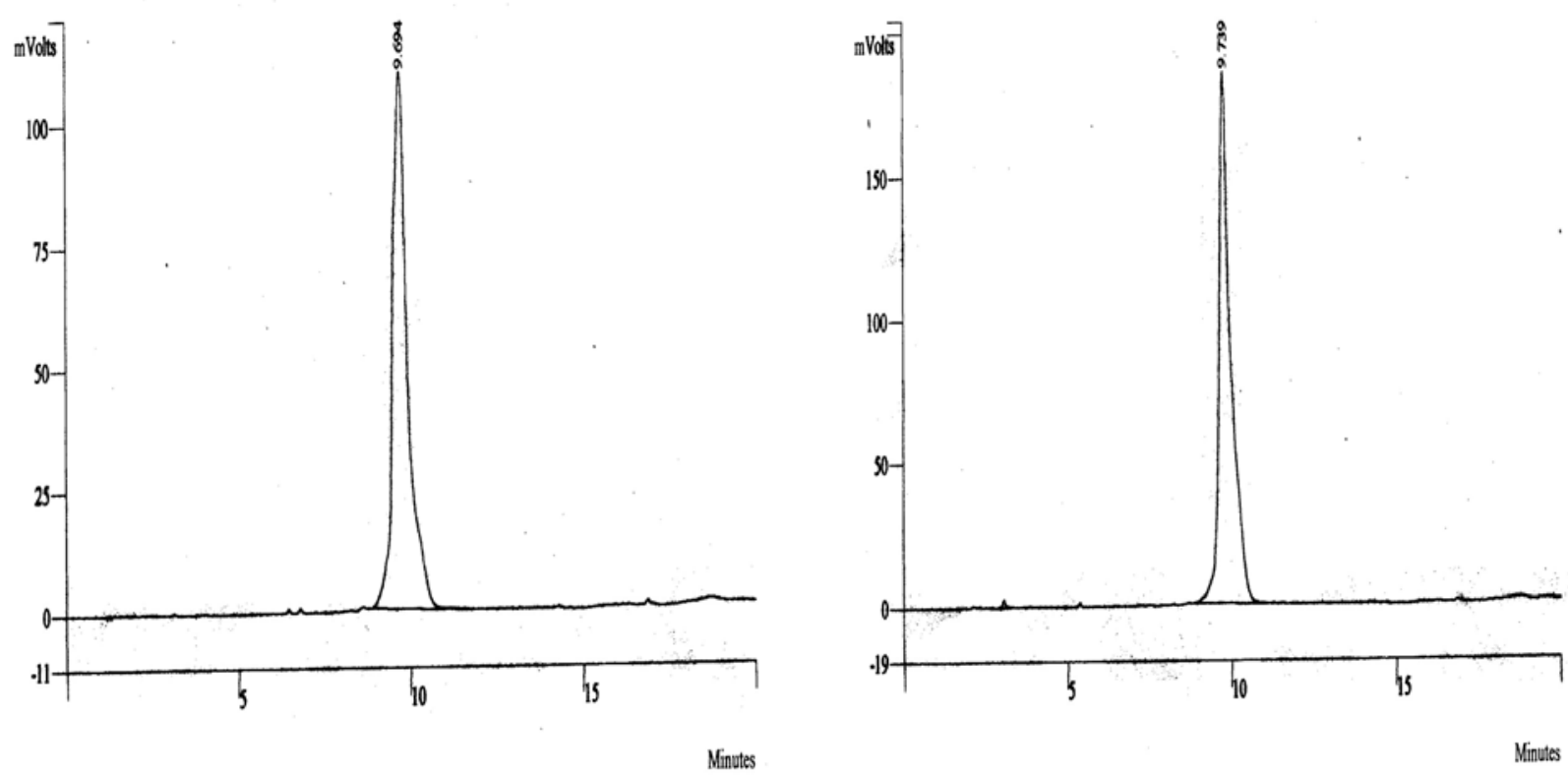

Peak
$\mathrm{N}_{0}$ Result 0 Ret Time (min) $\begin{gathered}\text { Peak Area } \\ \text { (counts) }\end{gathered}$ Width $1 / 2$ (sec)

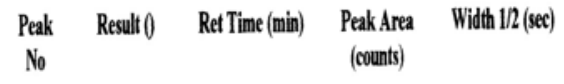

$\frac{1}{100.0000}-9.694-\frac{3326913}{30926913}-25.4$

$\frac{1}{100.0000}-9.739-\frac{4632538}{4630.0000}-19.2$




\section{S7}

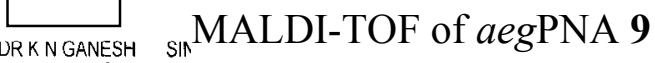

Tg9

Data: TGTG90001.3 $7 \mathrm{Jul} 2003$ 15:22 Cal: tof 8 Dec 2000 11:00

Kratos PCKompact SEQ V1.2.2: + Linear High, Power: 143, P.Ext. @ 3500 (bin 254)

$\%$ Int. $\quad 100 \%=10 \mathrm{mV}[\mathrm{sum}=521 \mathrm{mV}]$ Profiles $1-50$ Smooth Av 50
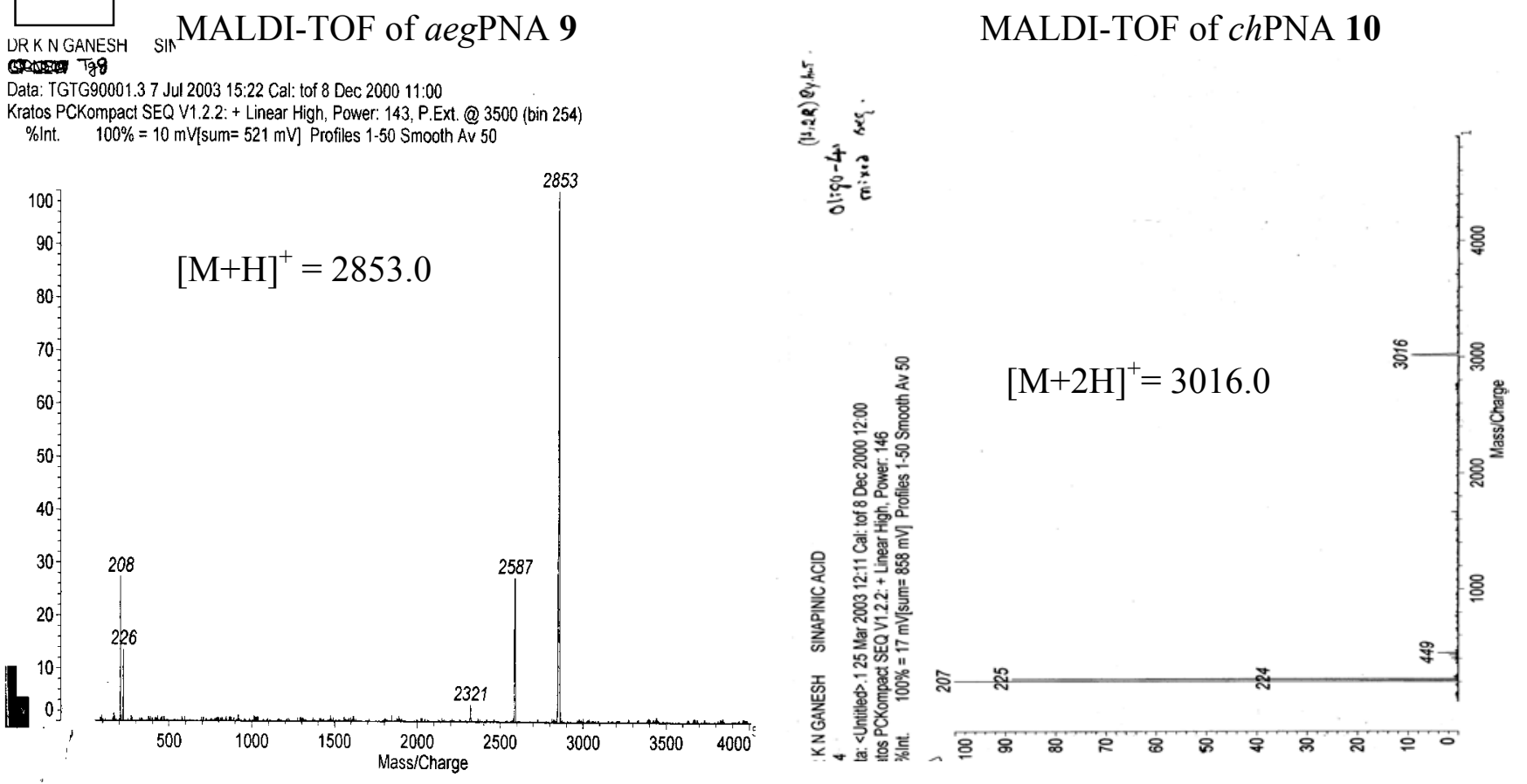

MALDI-TOF of $c p$ PNA 11

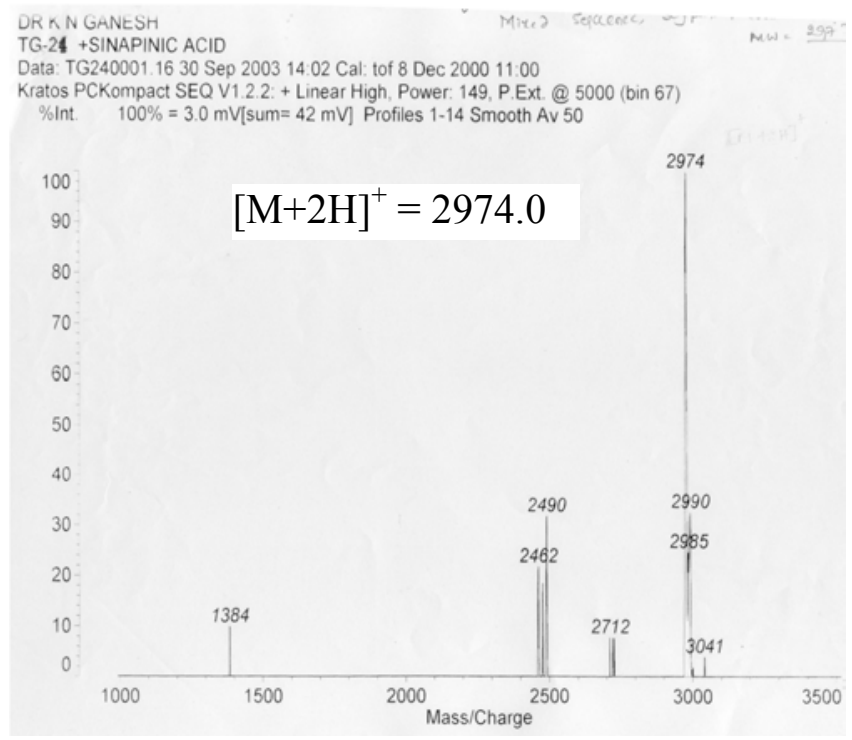




\section{S8}

Table 2. HPLC and MALDI-TOF mass spectral analysis of synthesized PNAs.

\begin{tabular}{|c|c|c|c|c|c|}
\hline Entry & PNA Sequences & R.T (min) ${ }^{\mathrm{a}}$ & MF & $\mathrm{MW}_{\mathrm{Calc}}$ & $\mathrm{MW}^{\mathrm{b}}{ }_{\text {obs }}$ \\
\hline 1 & aegPNA 9, GTAGATCACT-LysNH 2 & 10.50 & $\mathrm{C}_{114} \mathrm{H}_{147} \mathrm{~N}_{60} \mathrm{O}_{31}$ & 2852.0 & 2853.0 \\
\hline 2 & chPNA 10, Gt $\mathbf{t}_{S R} \mathrm{AGAt}_{S R} \mathrm{CACt}_{S R},-\mathrm{LysNH}_{2}$ & 10.64 & $\mathrm{C}_{126} \mathrm{H}_{165} \mathrm{~N}_{60} \mathrm{O}_{31}$ & 3014.0 & 3016.0 \\
\hline 3 & $c h$ PNA 11, Gt ${ }_{R S} \mathrm{AGAt}_{R S} \mathrm{CACt}_{R S}-\mathrm{LysNH}_{2}$ & 10.71 & $\mathrm{C}_{126} \mathrm{H}_{165} \mathrm{~N}_{60} \mathrm{O}_{31}$ & 3014.0 & 3016.0 \\
\hline 4 & $c p$ PNA 12, Gt $\mathbf{t}_{S R} \mathrm{AGAt}_{S R} \mathrm{CACt}_{S R}-\mathrm{LysNH}_{2}$ & 9.69 & $\mathrm{C}_{123} \mathrm{H}_{159} \mathrm{~N}_{60} \mathrm{O}_{31}$ & 2972.0 & 2974.0 \\
\hline 5 & $\begin{array}{l}c p \text { PNA 13, Gt } t_{R S} \mathrm{AGAt}_{R S} \mathrm{CACt}_{R S}-\mathrm{LysNH}_{2} \\
\text { p53 }\end{array}$ & 9.73 & $\mathrm{C}_{123} \mathrm{H}_{159} \mathrm{~N}_{60} \mathrm{O}_{31}$ & 2972.0 & 2974.0 \\
\hline 6 & aegPNA 18, GGCAGTGCCT-LysNH ${ }_{2}$ & 7.99 & $\mathrm{C}_{113} \mathrm{H}_{146} \mathrm{~N}_{61} \mathrm{O}_{32}$ & 2870.0 & 2871.1 \\
\hline 7 & chPNA 19, GGCAGt SR $_{\mathrm{SR}} \mathrm{GCT}-\mathrm{LysNH}_{2}$ & 9.10 & $\mathrm{C}_{117} \mathrm{H}_{152} \mathrm{~N}_{61} \mathrm{O}_{32}$ & 2924.0 & 2925.5 \\
\hline 8 & chPNA 20, GGCAGt SR $_{\mathrm{SR}} \mathrm{GCC}_{\mathrm{SR}}-\mathrm{LysNH}_{2}$ & 10.28 & $\mathrm{C}_{121} \mathrm{H}_{158} \mathrm{~N}_{61} \mathrm{O}_{32}$ & 2978.0 & 2979.0 \\
\hline 9 & chPNA 21, GGCAGt ${ }_{\mathrm{RS}} \mathrm{GCCT}-\mathrm{LysNH}_{2}$ & 9.51 & $\mathrm{C}_{117} \mathrm{H}_{152} \mathrm{~N}_{61} \mathrm{O}_{32}$ & 2924.0 & 2925.1 \\
\hline 10 & chPNA 22, GGCAGt GS GCCt $_{\mathrm{RS}}-\mathrm{LysNH}_{2}$ & 10.17 & $\mathrm{C}_{121} \mathrm{H}_{158} \mathrm{~N}_{61} \mathrm{O}_{32}$ & 2978.0 & 2979.3 \\
\hline
\end{tabular}

${ }^{a}$ R.T $=$ Retention time (HPLC) in minutes. $\mathrm{MF}=$ Molecular formula. $\mathrm{MW}_{\text {calc }}=$ Molecular weight calculated from the corresponding Molecular formula. $\mathrm{MW}_{\mathrm{obs}}=$ Molecular weight observed, measured on MALDI-TOF spectrometry (for details see experimental section). Where $\mathbf{t}_{S R} / \mathbf{t}_{R S}=(1 S, 2 R) /(1 R, 2 S)$-cyclohexanyl or $(1 S, 2 R) /(1 R, 2 S)$-cyclopentanyl thymine units. 


\section{S9}

UV-Tm measurements: The complementary DNA oligomers were synthesized on an Applied Biosystems 3900 DNA Synthesizer. The complementary RNA sequences were obtained from SigmaAldrich. The concentration was calculated on the basis of absorbance from the molar extinction coefficients of the corresponding nucleobases. The complexes were prepared in $10 \mathrm{mM}$ sodium phosphate buffer, pH 7.0 containing $\mathrm{NaCl}(100 \mathrm{mM})$ and EDTA $(0.1 \mathrm{mM})$ and were annealed by keeping the samples at $90^{\circ} \mathrm{C}$ for 5 minutes followed by slow cooling to room temperature. Absorbance versus temperature profiles were obtained by monitoring at $260 \mathrm{~nm}$ with Perkin-Elmer Lambda 35 spectrophotometer scanning from 5 to $90^{\circ} \mathrm{C}$ at a ramp rate of $0.2^{\circ} \mathrm{C}$ per minute. The data were processed using Microcal Origin 5.0 and $T_{\mathrm{m}}$ values derived from the derivative curves.

Circular Dichroism: CD spectra were recorded on a JASCO J-715 spectropolarimeter. The CD spectra of the PNA:DNA complexes and the relevant single strands were recorded in $10 \mathrm{mM}$ sodium phosphate buffer, $100 \mathrm{mM} \mathrm{NaCl}, 0.1 \mathrm{mM}$ EDTA, $\mathrm{pH}$ 7.0. The temperature of the circulating water was kept below the melting temperature of the PNA:DNA complexes, i. e., at $10^{\circ} \mathrm{C}$. The CD spectra of the single strand PNAs were recorded as an accumulation of 10 scans from 320 to $195 \mathrm{~nm}$ using a $1 \mathrm{~cm}$ cell, a resolution of $0.1 \mathrm{~nm}$, band-width of $1.0 \mathrm{~nm}$, sensitivity of $2 \mathrm{~m}$ deg, response $2 \mathrm{sec}$ and a scan speed of $50 \mathrm{~nm} / \mathrm{min}$. for the PNA:DNA/RNA complexes, spectra were recorded as an accumulation of 8 scans, response of 1 sec and a scan speed of $200 \mathrm{~nm} / \mathrm{min}$. CD spectra of chPNA and cpPNA monomers were measured in methanol by the accumulation of 5 scans. 


\section{S10}
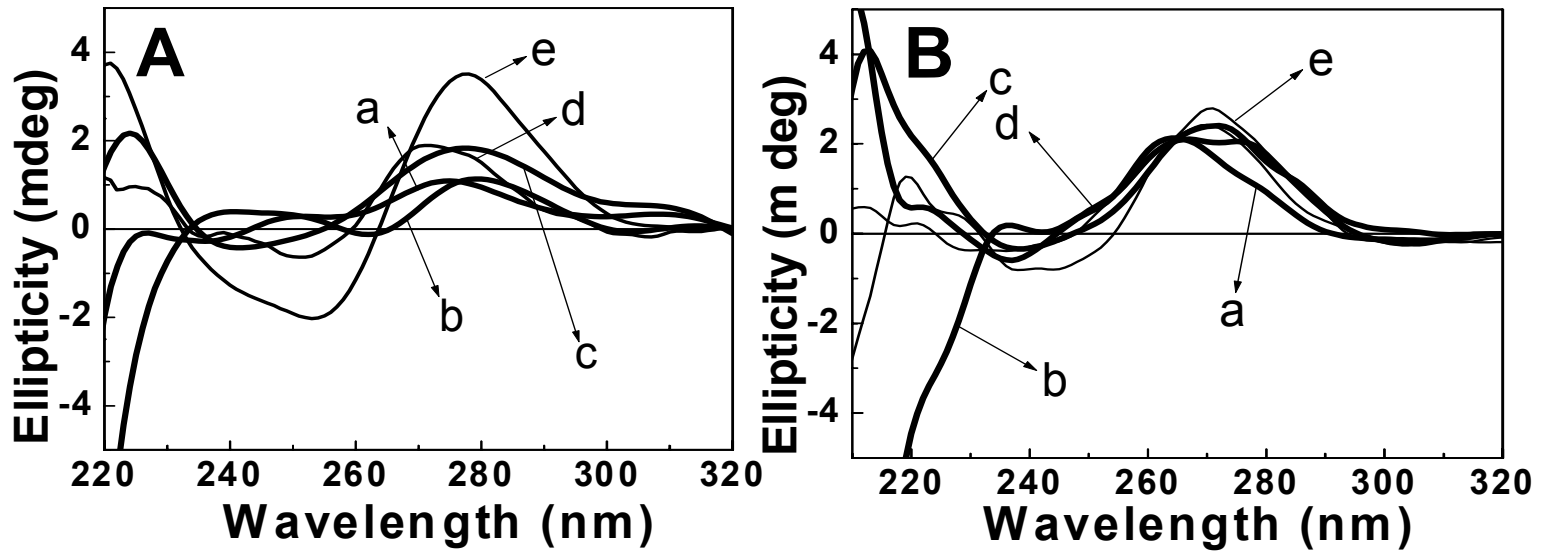

Figure. CD-profiles (A) PNA:DNA 14 and (B) PNA:RNA 15 duplexes. a. 9, b. 10, c. 11, d. 12, e. 13. Buffer: Sodium phosphate $(10 \mathrm{mM}), \mathrm{pH} 7.0$ with $100 \mathrm{mM} \mathrm{NaCl}$ and $0.1 \mathrm{mM}$ EDTA, $10^{\circ} \mathrm{C}$. DNA 14, 5'-AGTGATCTAC-3'(ap); RNA 15, 5'-AGUGAUCUAC-3'(ap).
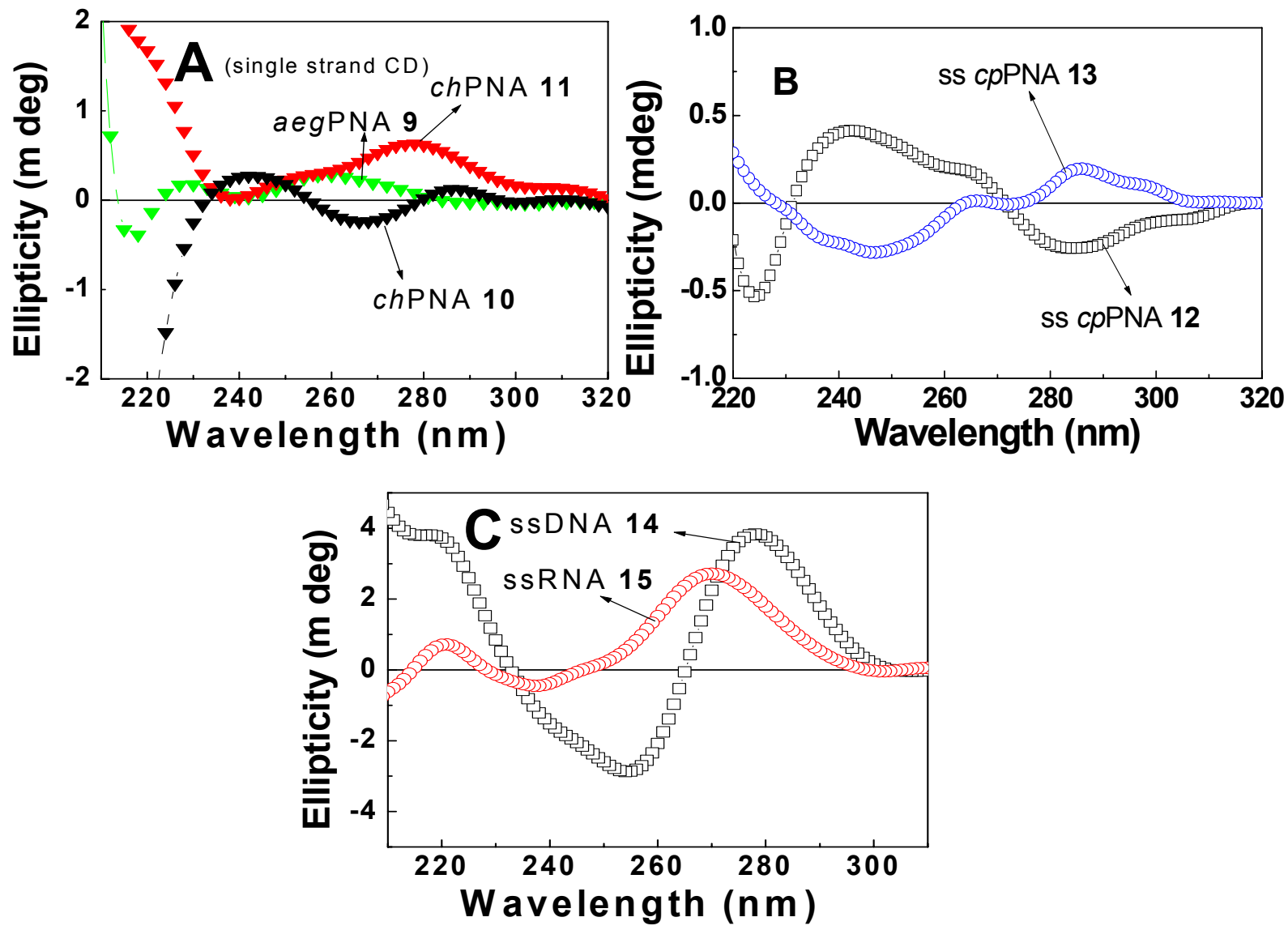

Figure. CD-curves of single stranded A: a) aegPNA 9, b) chPNA 10, c) chPNA 11, B: a) $c p$ PNA 12, b) $c p$ PNA 13, C: a) DNA 14, b) RNA 15. 

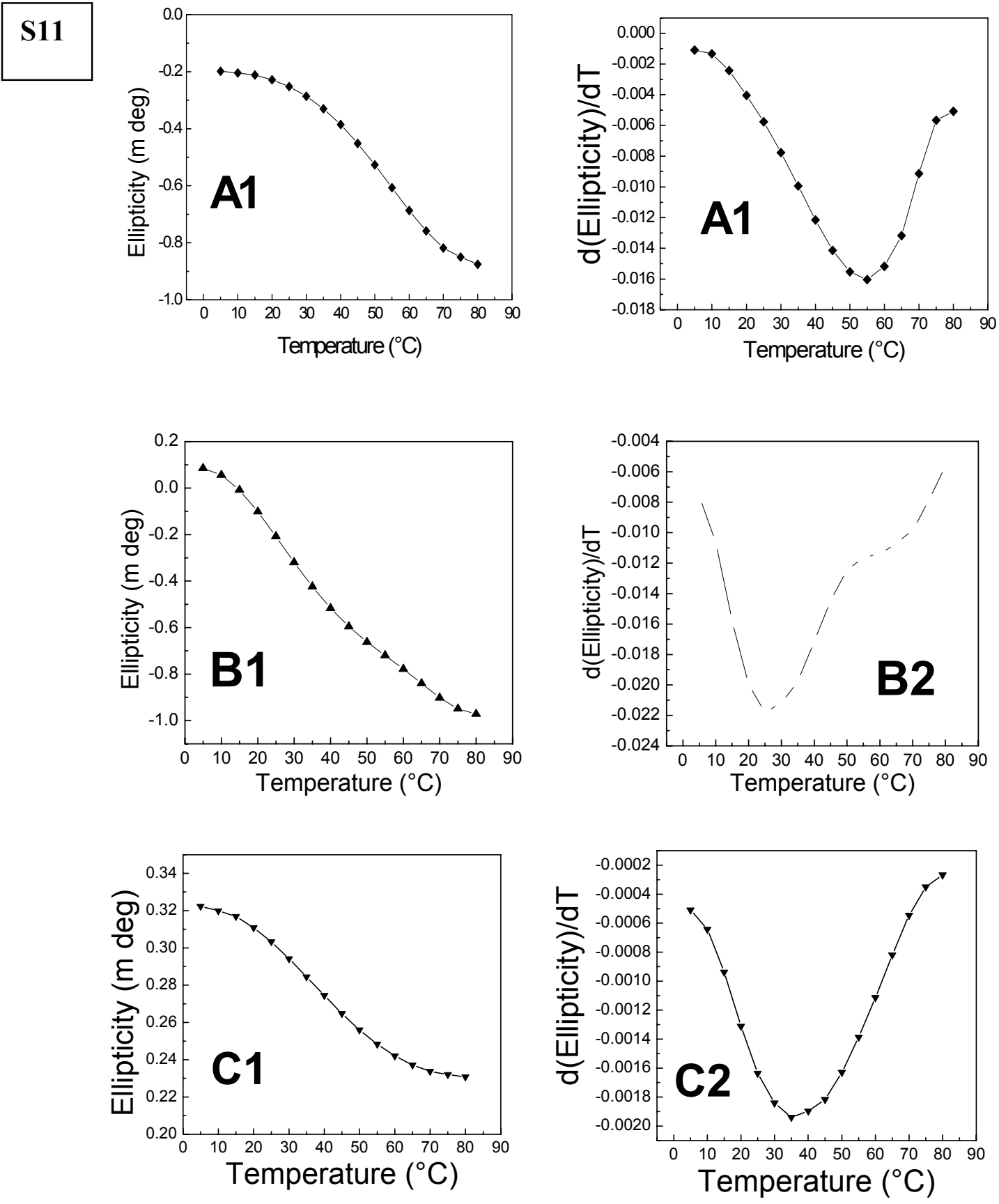

Figure. CD- $T_{\mathrm{m}}$ curves for duplexes of aegPNA 9, $c h$ PNA 10, chPNA 11 with DNA 14 (A1, B1, C1 respectively) and their corresponding derivative (A2, B2, C2). (10 mM sodium phosphate buffer, $\mathrm{pH}=7,100 \mathrm{mM}, \mathrm{NaCl}, 0.1 \mathrm{mM}$ EDTA) 
S12
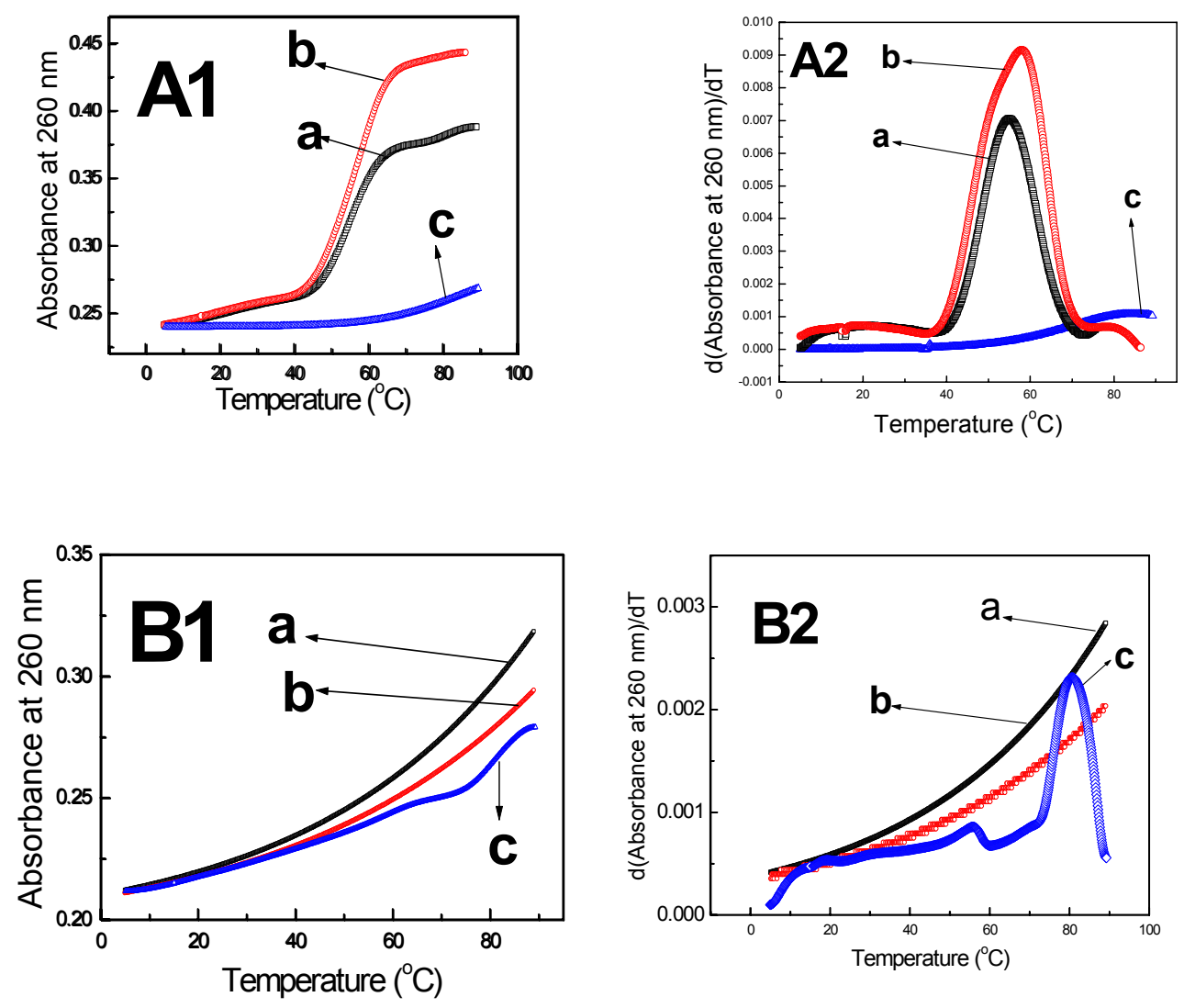

Figure. A1. Melting-curves of (a) aegPNA 9, (b) $\operatorname{ch}$ PNA 10, (c) chPNA 11 with RNA 15; A2. Corresponding first derivative curves: B1. Melting-curves of (a) aegPNA 9, (b) $c h$ PNA 10, (c) chPNA 11 with RNA 17; B2. Corresponding first derivative curves. 
S13
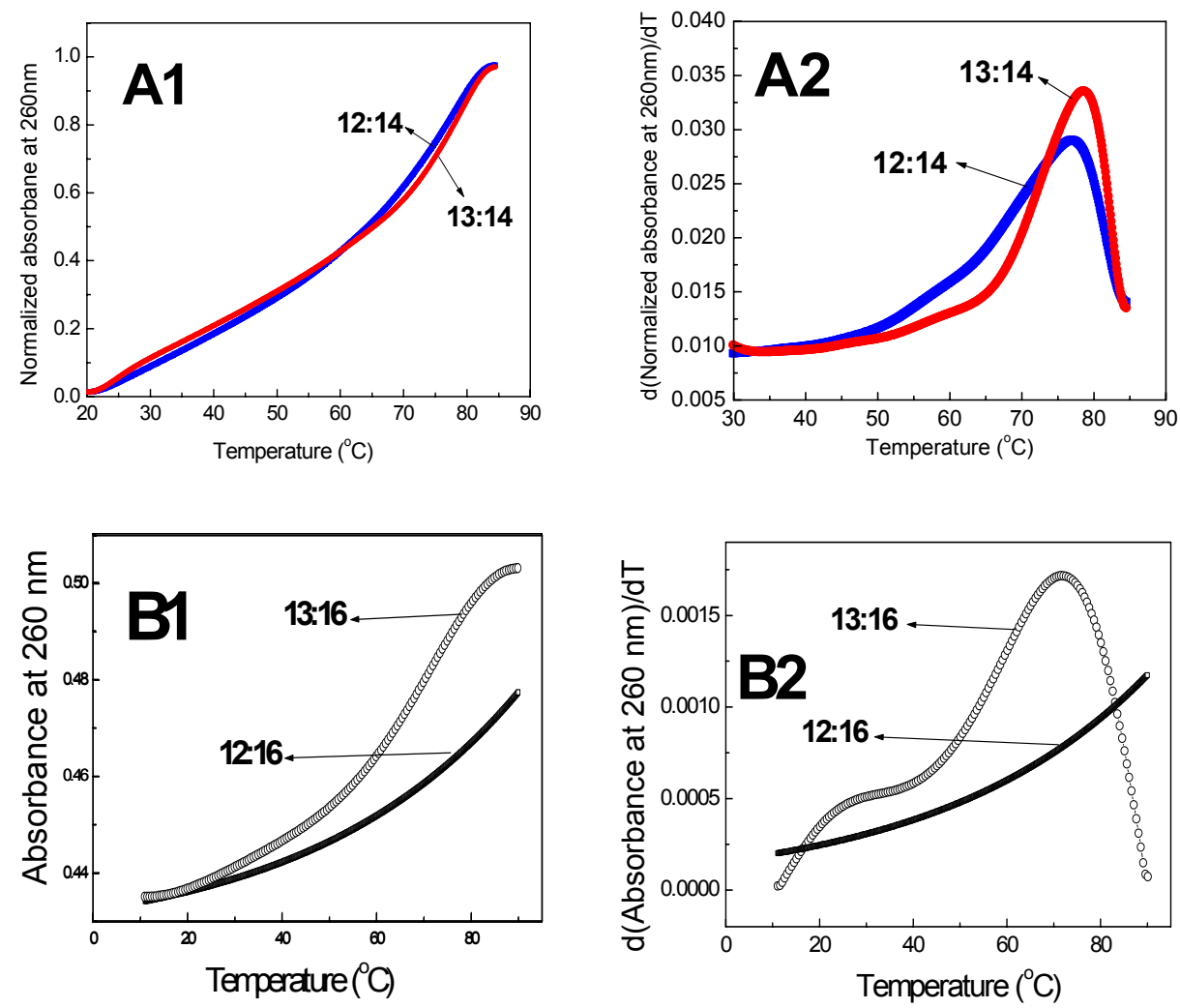

Figure. A1: Melting profiles of $c p$ PNA 12, $c p$ PNA 13 with DNA 14, A2: Corresponding derivative curves B1: Melting profiles of $c p$ PNA 12, $c p$ PNA 13 with DNA 16, B2: Corresponding derivative curves. 
S14
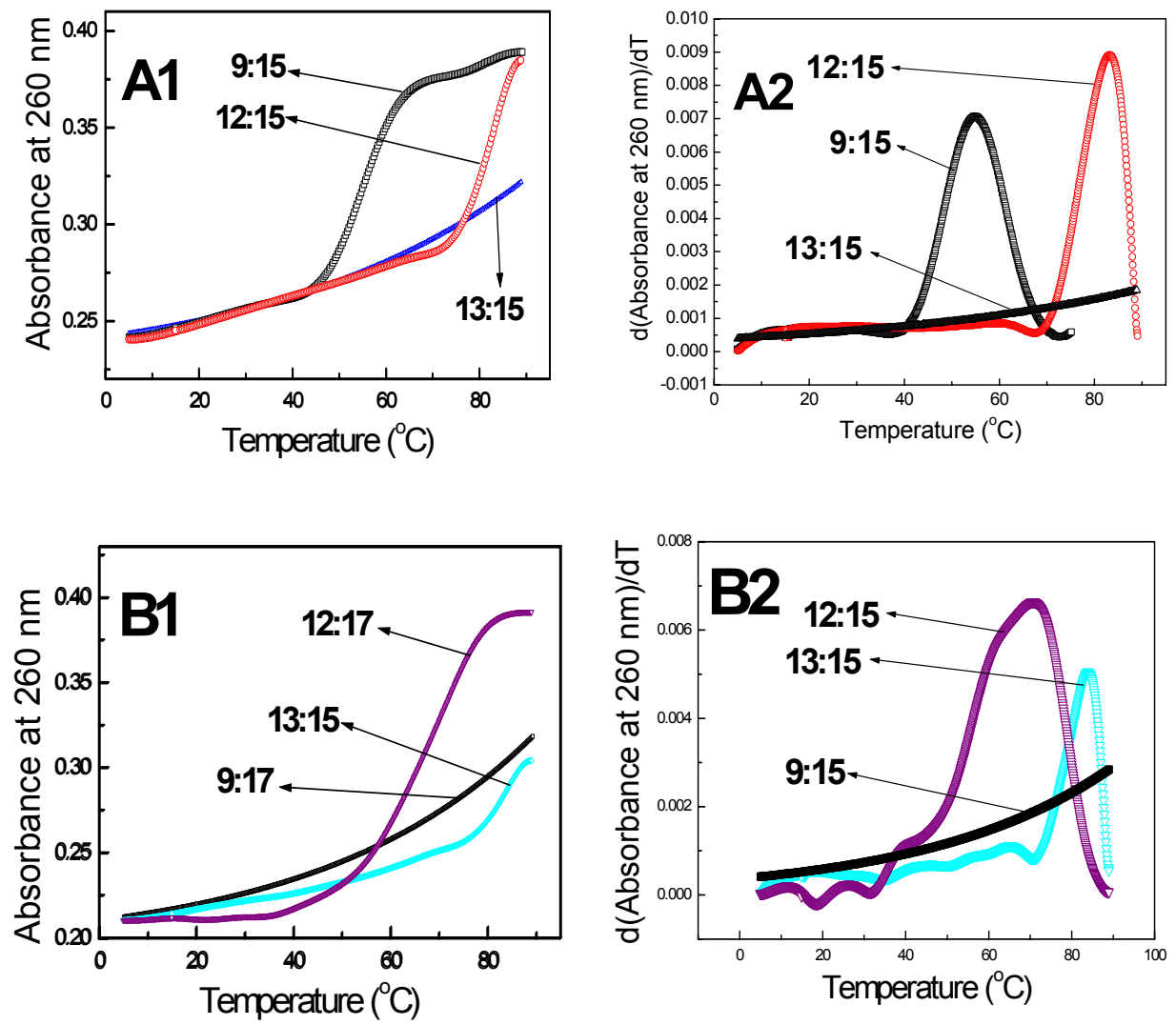

Figure. A1: Melting profiles of aegPNA 9, $c p$ PNA 12, $c p$ PNA 13 with RNA 15, A2: Corresponding derivative curves B1: Melting profiles of aegPNA 9, $c p$ PNA 12, $c p$ PNA 13 with RNA 17, B2: Corresponding derivative curves 
S15

HPLC profile of aegPNA 18

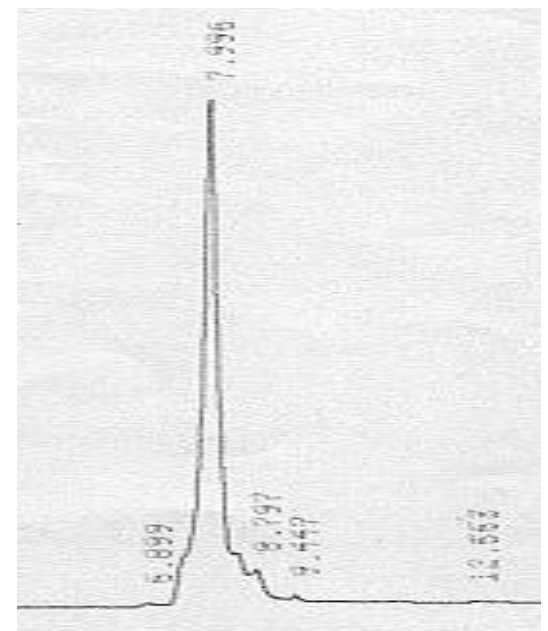

HPLC profile of $c h$ PNA 20

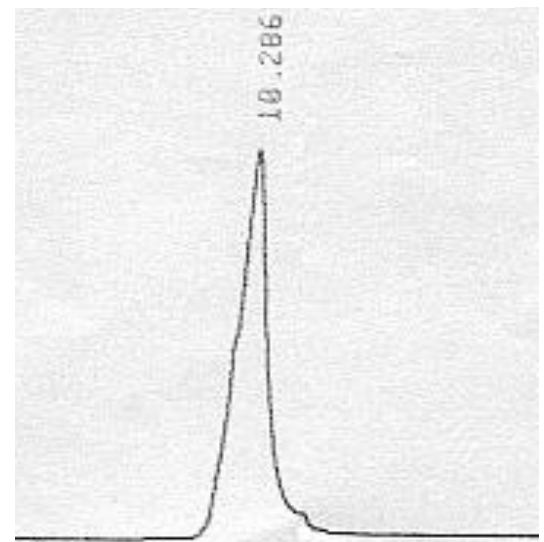

HPLC profile of $c h$ PNA 19

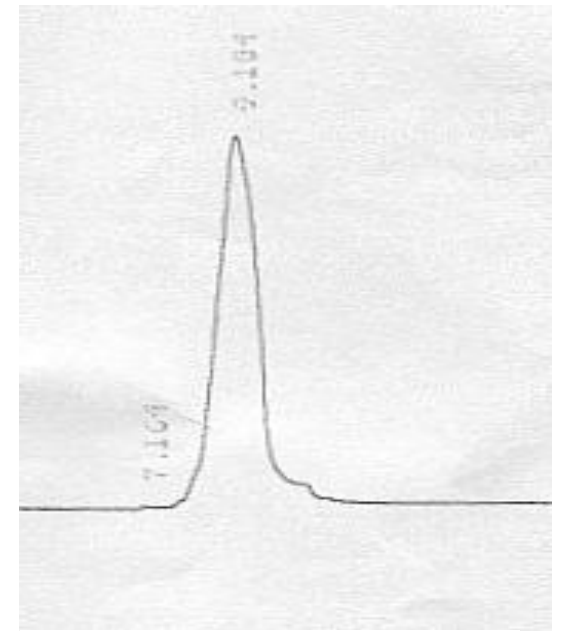

HPLC profile of $\operatorname{chPNA} 21$

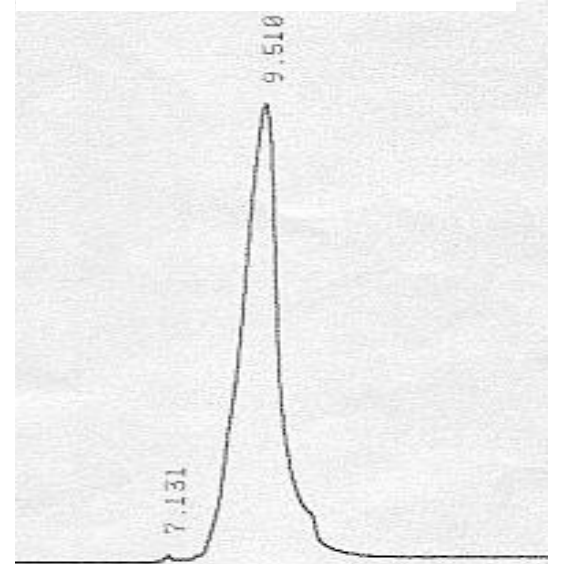

HPLC profile of chPNA 22

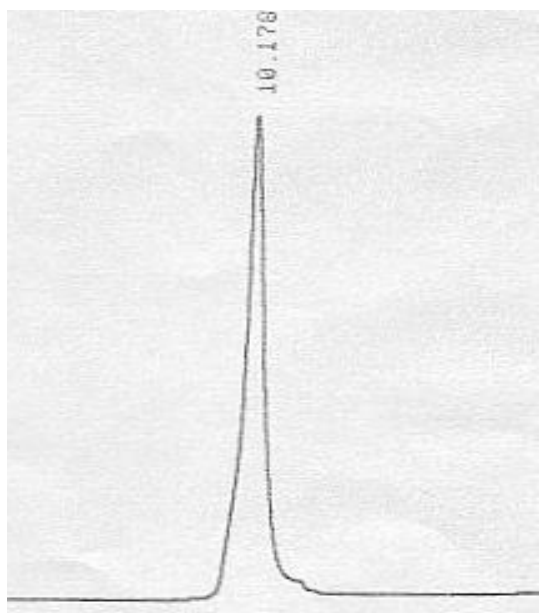

Figure. Reverse phase HPLC profiles of chPNAs 18-22. (For HPLC conditions see experimental section) 


\section{S16}

MALDI-TOF of aegPNA 18.

MALDI-TOF of $c h$ PNA 19.
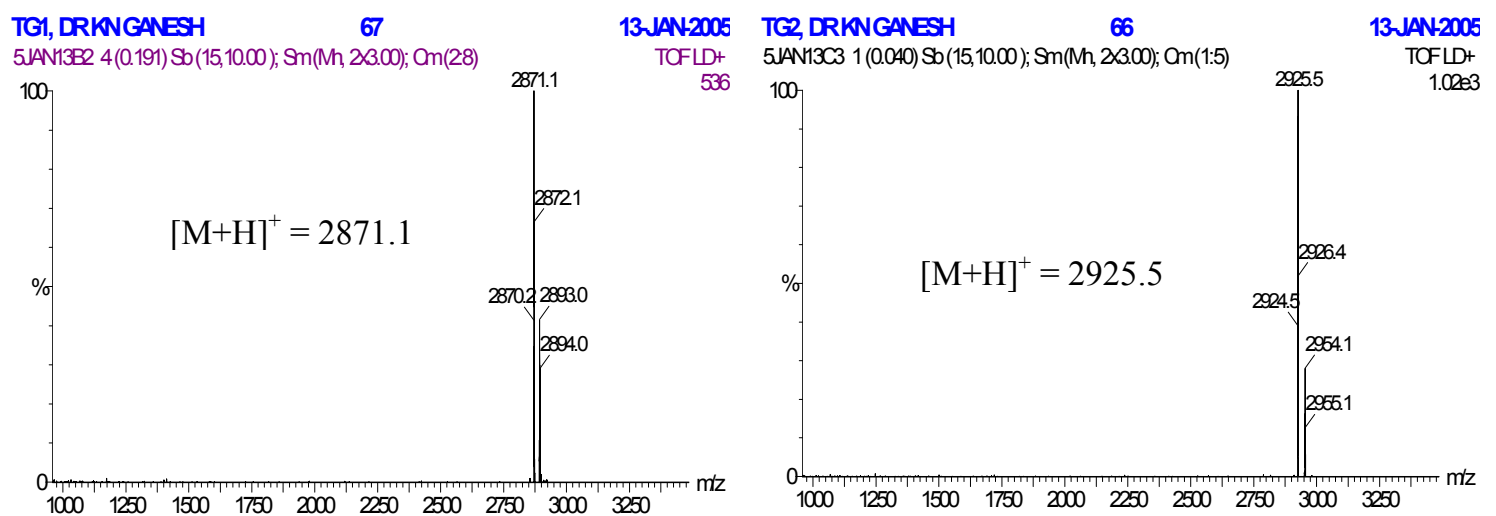

MALDI-TOF of $c h$ PNA 20.

MALDI-TOF of $c h$ PNA 21.
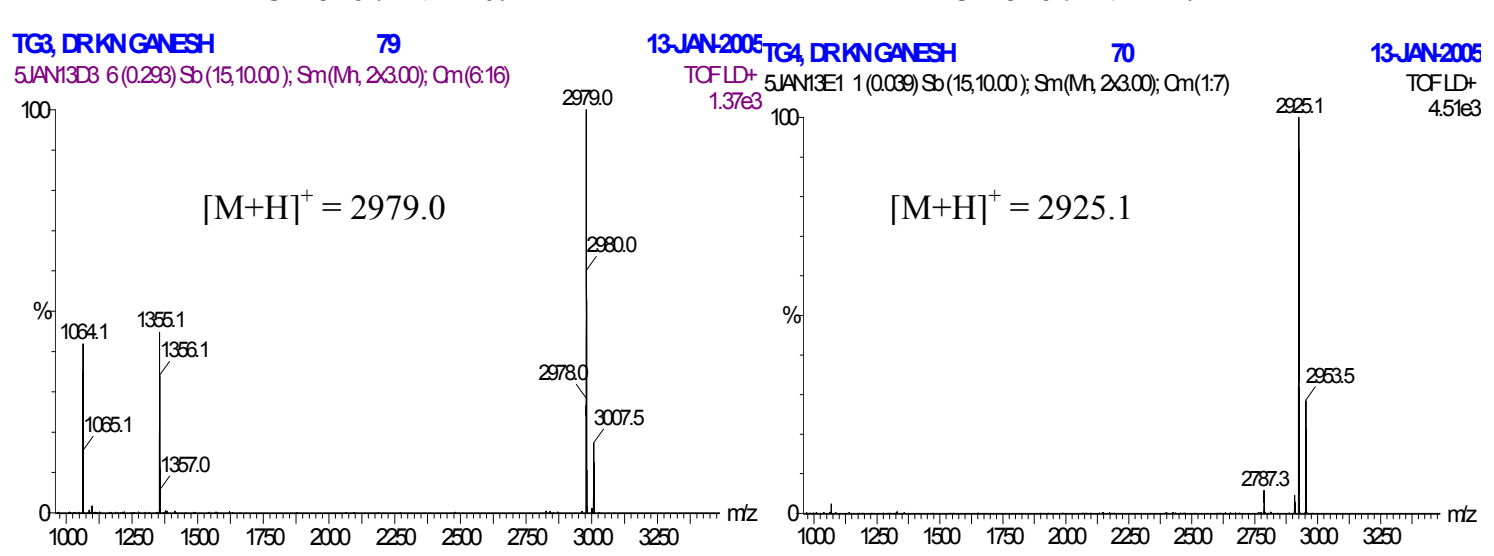

MALDI-TOF of chPNA 22.

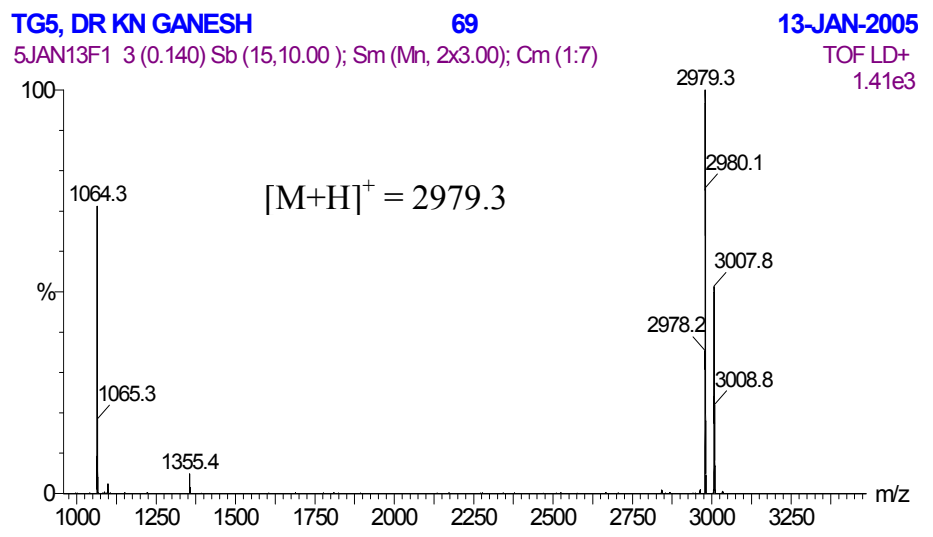



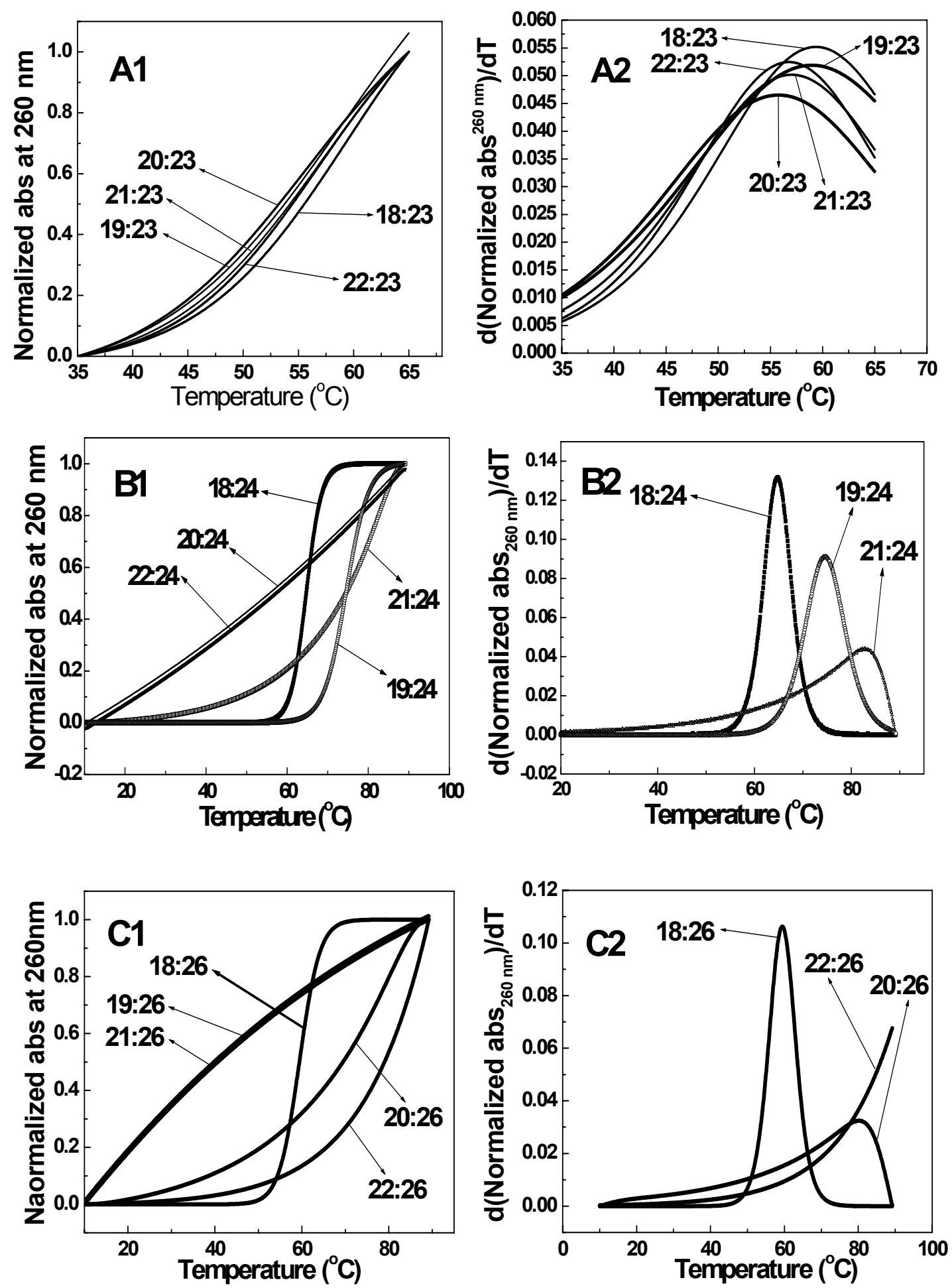

Figure. UV- $T_{\mathrm{m}}$ curves for PNA:DNA/RNA antiparallel duplexes of aegPNA 18, SR-chPNA 19, SR-chPNA 20, $R S$ chPNA 21, and $R S$-chPNA 22 with DNA 23 (A1) and RNA 24 (B1). C1: melting curves of PNA:RNA Parallel duplexes. A2, B2, C2: corresponding derivative. DNA 23 (antiparallel) = 5'-AGGCACTGCC-3', RNA 24 (antiparallel) = 5'-AGGCACUGCC-3', RNA 26 (parallel) = 5'-CCGUCACGGA-3' (10 mM sodium phosphate buffer, $\mathrm{pH}=7,100 \mathrm{mM}, \mathrm{NaCl}, 0.1 \mathrm{mM}$ EDTA) 


\section{S18}

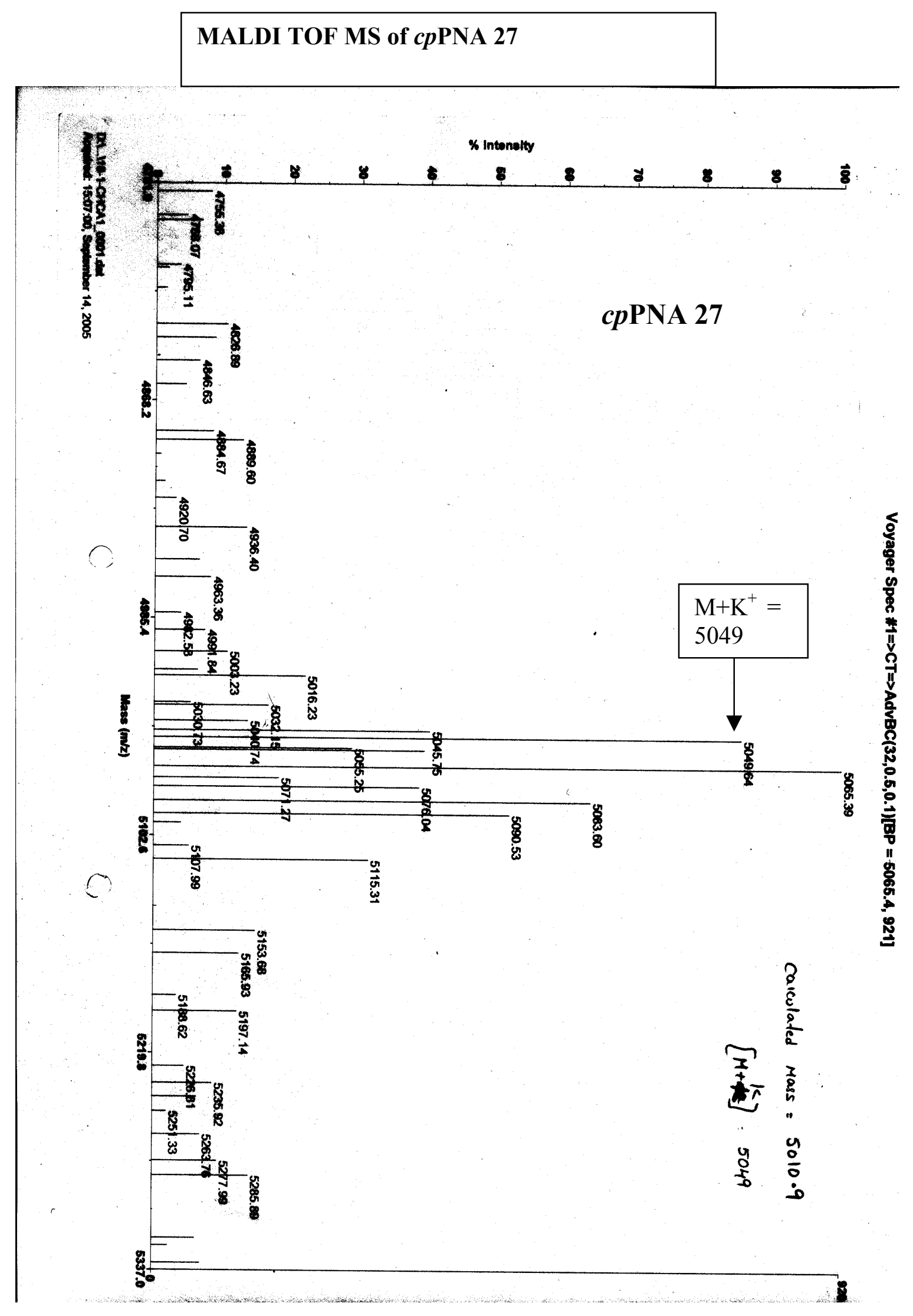




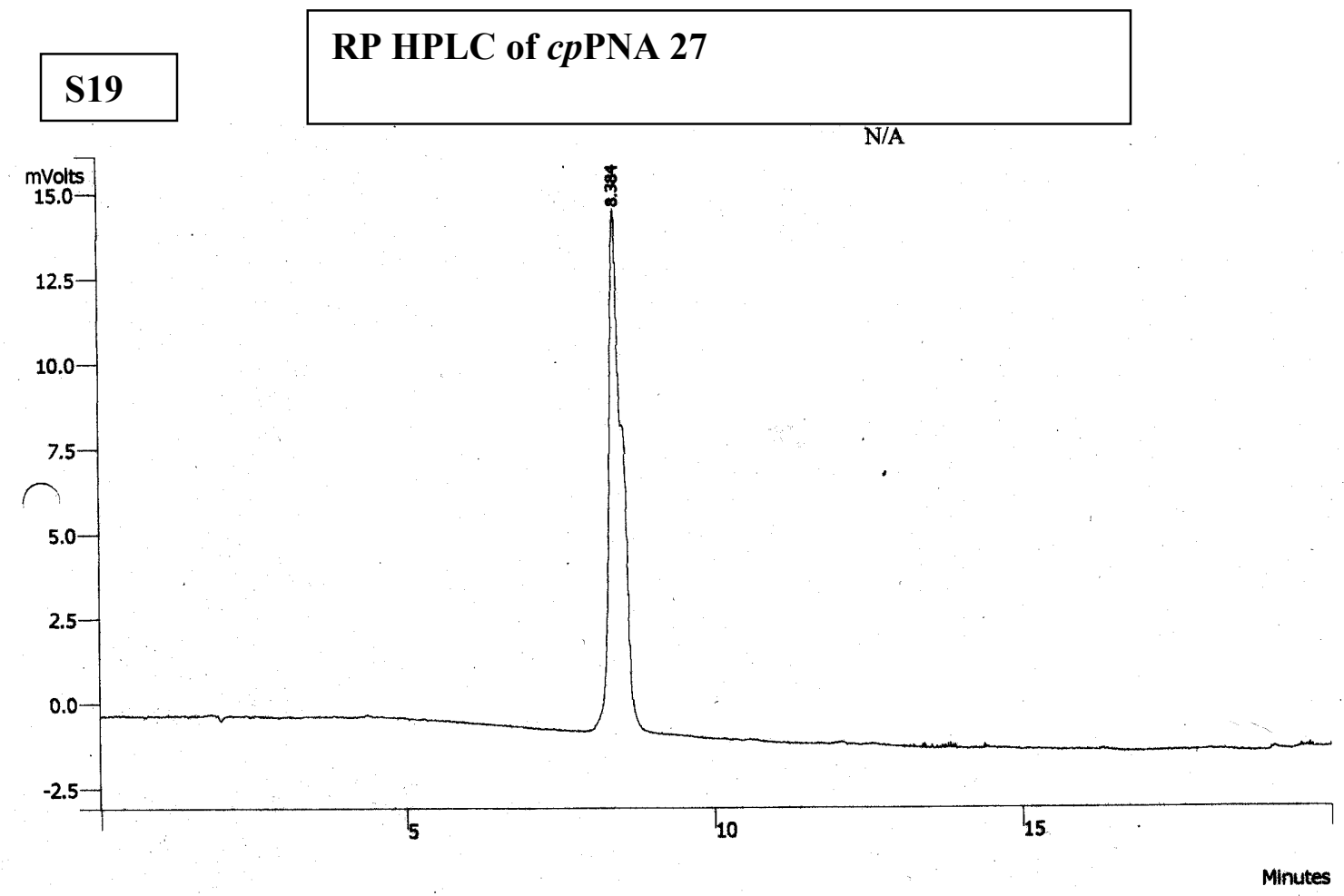


cpPNA $275^{\prime}$ H-CCT CtT ACC tCA GTt ACA-LysNH ${ }_{2}$

DNA 28 5'-TGT AAC TGA GGT AAG AGG-3' [DNA complementary (antiparallel)]

DNA 29 5'-GGA GAA TGG AGT CAA TGT-3' [DNA complementary (parallel)]

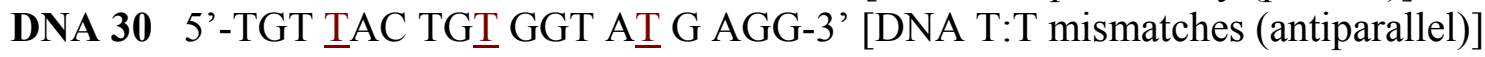

DNA 31 5'- TGT AAC TG $\underline{C}$ GGT AAG AGG-3'[DNA T:C mismatch (antiparallel)]

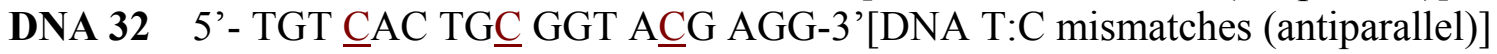

RNA 33 r (5'-GGA GAA UGG AGU CAA UGU-3'). [RNA complementary (parallel)]

RNA 34 r (5'-GGA GAA UGC AGU CAA UGU-3') [RNA T:C mismatch (parallel)]

Thermal denaturation was carried out in $10 \mathrm{mM}$ phosphate buffer ( $\mathrm{pH} 7.4)$ and $10 \mathrm{mM} \mathrm{NaCl}$

concentration. Curves were obtained by recording the absorbance at $260 \mathrm{~nm}$ from 10 to $85^{\circ} \mathrm{C}$ at ramp $0.5^{\circ} \mathrm{C} \mathrm{min}^{-1}$. Experiments were done in $0.5 \mu \mathrm{M}$ concentrations. All values are an average of three independent experiments and accurate to within $\pm 0.5^{\circ} \mathrm{C}$. 
UV.melting profiles of cpPNA 27:DNA/RNA duplexes

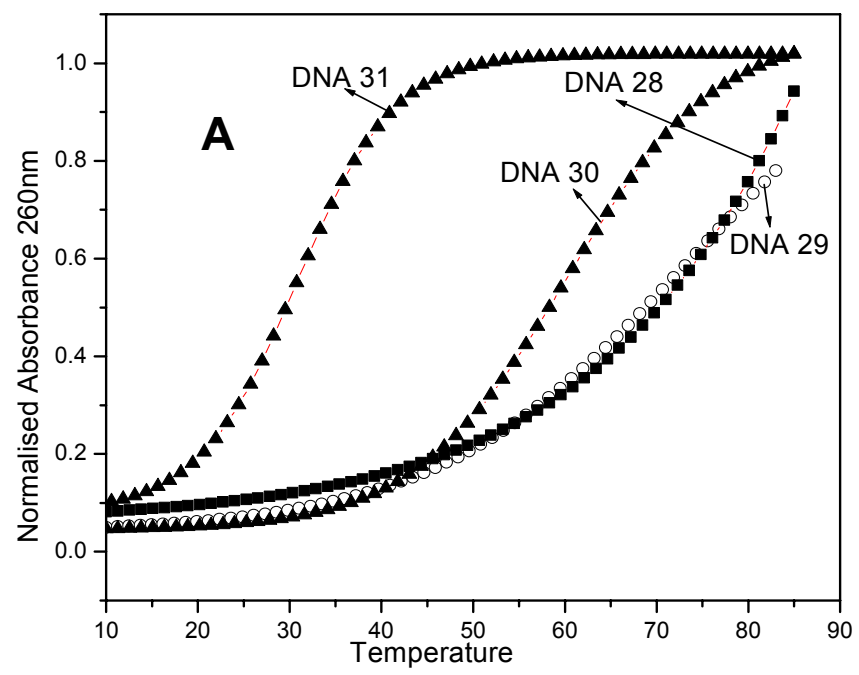

Melting profiles of $c p$ PNA 27 with DNA 28, DNA 29, DNA 30, DNA 31

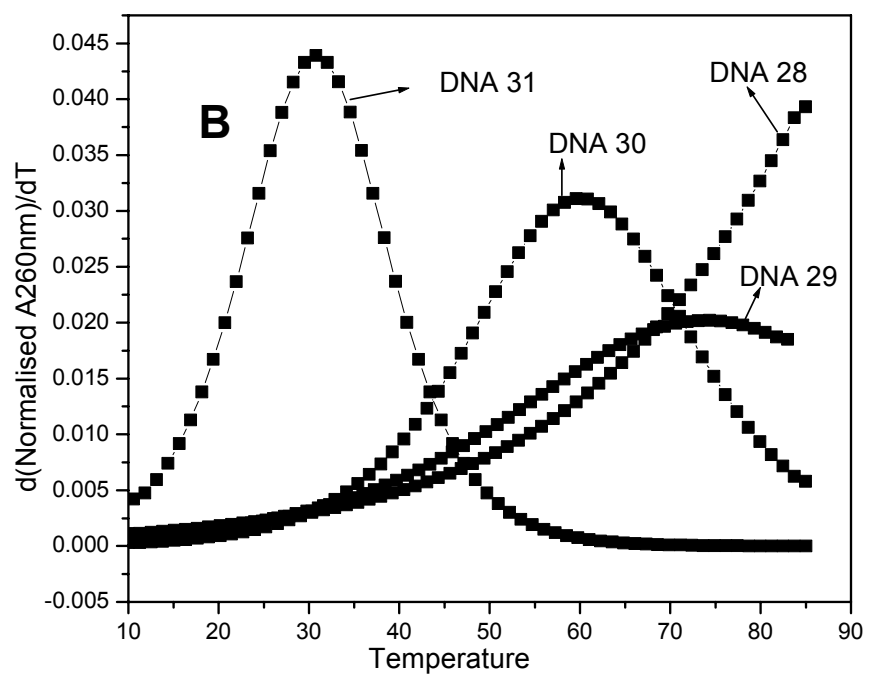

Derivative curves

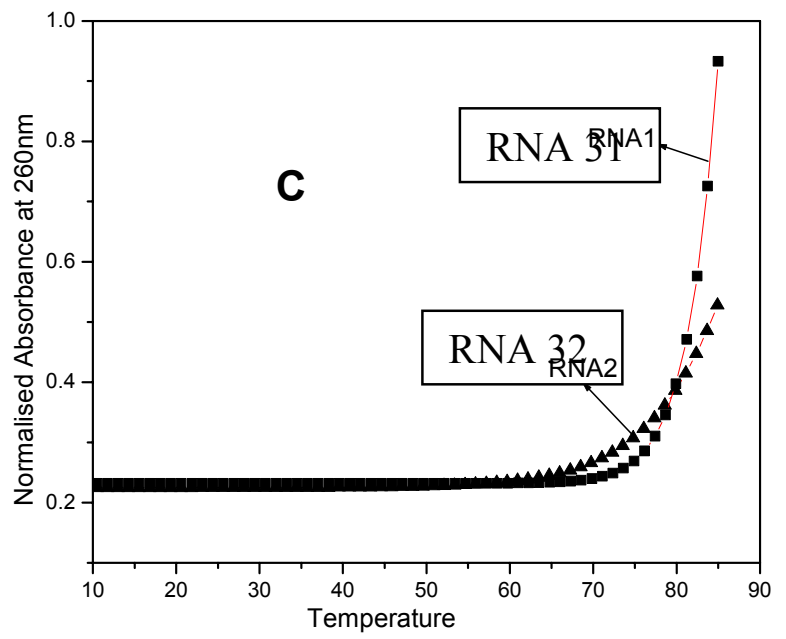

